\title{
Life Skill Development and its Impact on Perceived Stress, Employment and Education Pursuits: A Study of Young Adults with a History of Homelessness and Trauma
}

Josephine Beker

Thomas Jefferson University, Philadelphia, jo@jbeker.com

Tina M. DeAngelis

Thomas Jefferson University, tina.deangelis@jefferson.edu

Author(s) ORCID Identifier:

Josephine Beker:

(iD) https://orcid.org/0000-0002-9422-3568

Tina M. DeAngelis:

(iD) https://orcid.org/0000-0001-5686-8333

\section{Recommended Citation}

Beker, J., \& DeAngelis, T. M. (2021). Life Skill Development and its Impact on Perceived Stress, Employment and Education Pursuits: A Study of Young Adults with a History of Homelessness and Trauma. Student Journal of Occupational Therapy, 2(2), 15-27. https://doi.org/10.46409/001.XVOH2735

This Article is brought to you for free and open access by SOAR @ USA. It has been accepted for inclusion in Student Journal of Occupational Therapy by an authorized editor of SOAR @ USA. For more information, please contactsoar@usa.edu, erobinson@usa.edu. 


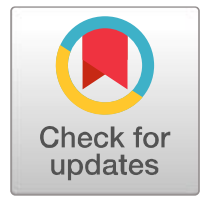

\title{
Life Skill Development and its Impact on Perceived Stress, Employment and Education Pursuits: A Study of Young Adults with a History of Homelessness and Trauma
}

\author{
Josephine Beker (D) Tina M. DeAngelis \\ Thomas Jefferson University
}

DOI: https://doi.org/10.46409/001.XVOH2735

To cite this article:

Beker, J. \& DeAngelis, T., (2021). Life skill development and its impact on perceived stress, employment and education pursuits: A study of young adults with a history of homelessness and trauma. Student Journal of Occupational Therapy, 2(1), 15-27. https://doi.org/10.46409/001.XVOH2735

Acknowledgements: The authors would like to acknowledge Nitasha Rivera, Barbara Hadley, Kate Gormley and Alexis Pugh for their professional guidance and for providing a location for group sessions; Maclain Capron for his feedback and assistance during data analysis; Dr. Henry Beker for proofreading assistance; and Bernadette Alpajora, Maura Gianonne, Ilyse Kramer and Carly Scheiner for early feedback on the manuscript.

Conflict of interest statement: This project was unfunded. No conflicts of interest are declared. This study was approved by Thomas Jefferson University's Institutional Review Board (Control \# 18D.768) on $1 / 23 / 19$.

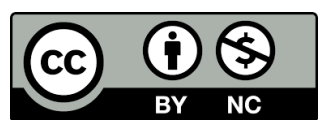

This article is licensed under the Creative Commons Attribution, Non-Commercial license (CC-BY-NC 4.0). You are free to copy and distribute the work under the following terms: You must give appropriate credit and include a link to the original work. This cover page or a standard citation including the DOI link will meet this term. You must also include the link to the CC-BY-NC license. You may not use the material for commercial purposes.

\begin{abstract}
An occupational therapy educational training group for young adults in permanent supported housing was developed, implemented and evaluated with pre-post outcome measures including Goal Attainment Scaling (GAS) and the Perceived Stress Scale-10 (PSS-10). This study explored stress levels and employment-related goals of individuals who have aged out of the foster care system and may also have had a history of chronic homelessness and trauma.

Results demonstrated a trend towards significance in perceived stress $(Z=1.689, p=0.91)$ with 7 of 8 participants surpassing the expected outcome according to GAS. Limitations included a small convenience sample $(n=8)$, inconsistent attendance and use of self-report measures.
\end{abstract}

Keywords: young adults, employment, homelessness, stress, occupational therapy, instrumental activities of daily living 


\section{Introduction}

Youth who age out of the foster care system have been shown to have increased rates of homelessness and criminal justice system involvement, as well as higher reports of mental illness and substance use secondary to trauma (Everson-Hock et al., 2011; Lee \& Morgan, 2017; Stewart et al., 2014). Intrafamilial trauma, both physical and psychological, has been shown to be one of the most consistent predictors of homelessness amongst young adults, with $48 \%$ of homeless youth reporting a history of sexual or physical abuse from a family member (Davies \& Allen, 2017). Once living on the streets, exposure to physical, psychological and sexual violence only increases with up to $85 \%$ of homeless youth reporting having witnessed or experienced one form of violence (Davies \& Allen, 2017). Continued exposure to violence and traumatic events is widely documented as a precursor to the development of post-traumatic stress disorder (PTSD) (Cougle et al., 2009; Davies \& Allen, 2017; Zona \& Milan, 2011). Homeless youth demonstrate a much higher risk of developing PTSD due to their consistent exposure to violence and crimes, and a lack of access to trauma-informed care often results in them carrying this diagnosis with them into young adulthood and beyond (Davies \& Allen, 2017).

Unstable employment and education patterns for these youth, including higher rates of high school dropouts and extended periods of unemployment, result in decreased access to postsecondary education, as well as low income being reported, particularly during late adolescence and early adulthood (Stewart et al., 2014; Villagrana et al., 2020). The high school graduation rate for young adults with a history of time spent in the foster care system is approximately $40 \%$ lower than that of the general population (Villagrana et al., 2020). The negative impact of homelessness on education outcomes amongst young adults has been shown to continue even once housing has been stabilized.

Among homeless persons, overall unemployment rates are high, with approximately $80-90 \%$ of the population currently out of work despite expressing a desire for consistent employment (Poremski et al.,
2017; Semanchin Jones et al., 2018). The correlation between homelessness and unemployment is further exacerbated by the fact that young adults who have a history of homelessness have difficulty gaining access to appropriate educational or vocational services (Ferguson et al., 2011). Assisting young adults to obtain and maintain employment is a major goal for organizations serving homeless youth (Ferguson, 2018). Employment, in which education plays a substantial role, is recognized nationally as a mechanism to decrease homelessness (Ferguson, 2018; Villagrana et al., 2020). Additionally, in comparison to the national average, youth who have aged out of the foster care system at the ages of 18 or 21 have been shown to have fewer support systems throughout their transition into adulthood (Lee \& Morgan, 2017; Stewart et al., 2014). Consequently, many individuals struggle to acquire employment, with those who do succeed demonstrating difficulty maintaining employment long term (Bond et al., 2015; Everson-Hock et al., 2011; Poremski et al., 2017; Stewart et al., 2014).

The ability to succeed within both academic and work environments has been shown to be positively correlated with an individual's capacity to manage both activities of daily living (ADLs), such as dressing, grooming, eating, and instrumental activities of daily living (IADLs), for example, finance/medication management, home maintenance and healthy communication (Barnow et al., 2013; Bond et al., 2015; Muñoz et al., 2005; Semanchin Jones et al., 2018; Thomas et al., 2011). Social participation, stress management, and coping skills, in particular, have also been shown to positively impact an individual's ability to both succeed within the educational setting as well as acquire and maintain employment (Muñoz et al., 2005; Semanchin Jones et al., 2018; Tandon et al., 2015; Thomas et al., 2011). In fact, combining interventions focused on improving the coping strategies of young adults with employment training has been shown to have an indirect, positive effect on employment outcomes through reducing depressive symptoms and improving engagement and motivation (Tandon et al., 2015). Many of these skills are developed during later adolescent years through the use of adult models 
and mentoring (Semanchin Jones et al., 2018). However, young adults with a history of time spent in the foster-care system, and/or of chronic homelessness, are often deprived of access to a stable and supportive environment in which these skills are developed (Semanchin Jones et al., 2018; Villagrana et al., 2020).

The benefits of vocational training programs as part of the services provided to homeless individuals by community-based organizations have been widely documented (Ferguson, 2018; Gray et al., 2017; Kannenberg \& Boyer, 1997; Poremski et al., 2017; Rosenheck \& Mares, 2007). Individuals with access to such vocational rehabilitation programs have demonstrated improvements in employment status, income, and work-related skills (Gray et al., 2017). To date, individual placement and support (IPS) has been shown to be the most effective form of evidence-based supported employment for homeless individuals with a history of mental illness (Bond et al., 2012; Ferguson, 2018; Marshall et al., 2014; Poremski et al., 2017). With competitive employment as the primary goal, and with mental health treatment integrated into employment services, IPS has been shown to be successful in assisting individuals to acquire employment in contrast to more traditional vocational services (Bond et al., 2015; Poremski et al., 2017; Rosenheck \& Mares, 2007). With a focus on a client-centered, 1:1 approach, and with an understanding of the way in which the environment can influence performance (Kukla \& Bond, 2009), IPS has similar values and principles to occupational therapy. However, IPS is limited to providing vocational and clinical services (Ferguson, 2018) with no specific focus on the additional IADL and stress management/coping skill areas described above, which have been identified as contributing to the poor employment and educational outcomes of young adults.

Beyond vocational training programs, additional support services provided to the homeless population, or to young adults who have aged out of the foster-care system, have been shown to be positively correlated with employment outcomes (Everson-Hock et al., 2011; Heerde, Hemphill, \& Scholes-Balog, 2018; Muñoz et al., 2005; Tandon et al., 2015; Thomas et al., 2011). Transition support services (TSS) offered to young adults by a range of state agencies and community-based organizations, function to promote a successful transition out of the foster-care system and into adulthood (Everson-Hock et al., 2011; Heerde et al., 2016). With a focus on basic living skills, including ADLs and IADLs (Everson-Hock et al., 2011), TSS are closely aligned with occupational therapy practice and function to target similar areas of need within this population. TSS have been shown to be positively correlated with employment outcomes, with those receiving services more likely to secure paid employment than those without access to such services (Everson-Hock et al., 2011; Heerde et al., 2016).

Motivation was also found to be a predictor of the success of many services offered, with levels of motivation positively correlated with employment outcomes (Ferguson, 2018; Hoven et al., 2016; Poremski et al., 2016). Completing the programs offered by services, in fact the process of employment seeking and acquisition as a whole, is often gradual requiring participants to demonstrate a level of individual motivation to continue with the process in light of any rejections or failures they may experience (Hoven et al., 2016). For those who have a history of trauma, these disappointments can be triggers for maladaptive responses which could result in them no longer pursuing employment outcomes due to fear of recurrent failure (Muldoon et al., 2019). Consequently, the external supports provided by services, such as IPS and TSS, strengthen individuals' motivation even in the face of perceived rejection and/or failure enabling them to continue their efforts toward employment acquisition and job maintenance (Bond et al., 2019; Hoven et al., 2016).

Over the past decade, there has been a gradual increase in publications discussing the impact of occupational therapy services with the homeless population. However, there are limited pre/post outcome studies capturing the impact of occupational therapy as an intervention particularly amongst young adults with a history of homelessness (Thomas et al., 2011). Nonetheless, common occupational needs and goals, such as 
finance management, anger management, time management and overall communication skills have been identified (Thomas et al., 2011). Occupational therapy has been shown to target these from a unique perspective, focusing on learning through active rather than passive participation with potentially promising results (Muñoz et al., 2005; Thomas et al., 2011). Vocational rehabilitation and guidance fall within the scope of occupational therapy practice, with occupational therapists able to function as members of interdisciplinary teams to support and enhance employment outcomes amongst the homeless population through focusing on life skill interventions (Muñoz et al., 2005; Thomas et al., 2011). A study completed by Muñoz et al. (2005), a 12-week life skills curriculum for adults, focused on the development of IADL and interpersonal skills, including stress management, budgeting and coping strategies, and delivered by an occupational therapist, was shown to positively impact multiple areas of employment, including employment acquisition and maintenance, for $96 \%$ of individuals who completed the full curriculum (Muñoz et al., 2005). Moreover, occupational therapy has demonstrated the ability to restore an individual's occupational balance, wherein they are able to achieve a successful integration of life activities and demands, which consequently holds the potential to remove barriers associated with successful role maintenance (employment and education) (Muñoz et al., 2005). As such, there is a need to further study the effect of occupational therapy, particularly IADL supports, to determine its impact on the employment and education outcomes of young adults with a history of homelessness and trauma.

\section{Purpose}

The primary purpose of this study was to determine the effectiveness of an occupational therapy educational training group ("Don't STRESS it!") on the education/employment-related goal achievement of young adults who have aged out of the foster-care system and who have a history of chronic homelessness and trauma. A secondary objective of the study was to explore individual participant perceived stress levels, pre-post implementation of the "Don't STRESS it!" group program. Additionally, knowledge gained could function to inform future occupational therapy programming designed to improve the employment outcomes of young adults.

\section{Methods}

\section{Description of Organization}

This study was completed as part of a university sponsored doctoral capstone project in conjunction with the employment services department of a nonprofit organization in the northeastern United States. The organization's employment services department received grant funding to provide an apprenticeship program to young adults residing within their facilities, with a focus on the exploration of employment and educational opportunities. Staff at the organization reported that while young adults demonstrated the ability to acquire employment with assistance through the current service model, maintaining employment continued to be an unsolved issue (Vice President of Residential \& Homeless Programs, personal communication, Sep 19, 2018). There were several barriers which were perceived as limiting employment outcomes amongst this population including work skills, stress management, coping skills, social participation, and ADL and IADL performance, which reflects findings within the literature (Barnow et al., 2013; Everson-Hock et al., 2011; Poremski et al., 2017; Stewart et al., 2014; Thomas et al., 2011). All of these areas fall under the scope of occupational therapy practice (AOTA, 2020) and subsequently highlighted a need for such services within the organization. Services currently offered to the young adults of the organization's sites included housing, healthcare, social enterprises, education and employment; employment services were provided through a supported employment model managed by employment specialists.

\section{Study Participants}

Study participants were recruited using convenience sampling. All participants resided at one of the organization's permanent supported 
housing facilities located in the Northeast section of the city. Of the 11 individuals enrolled in the organization's employment apprenticeship program, eight young adults were recruited for the "Don't STRESS it!" study and completed the full occupational therapy educational training group. Of the three who dropped out, two were due to unrelated health conditions, and one was removed by the organization secondary to behavioral issues. The final sample consisted of four female and four male participants $(\mathrm{n}=8)$.

Employment status of the participants at the time of programming ranged from unemployed, part-time or full-time employment status. All participants

Table 1

Demographic Characteristics of Sample

\begin{tabular}{|lc|}
\hline \multicolumn{1}{|c|}{ Variable } & $\begin{array}{c}\text { Percentage of } \\
\text { Sample (n=8) }\end{array}$ \\
\hline $\begin{array}{l}\text { Biological Sex } \\
\text { Male }\end{array}$ & 50 \\
\hline \multicolumn{1}{|c|}{ Female } & 50 \\
\hline Age & \\
\hline 21 & \\
\hline 22 & 25 \\
\hline 23 & 50 \\
\hline 24 & 12.5 \\
\hline Ethnicity & 12.5 \\
\hline Black/African American & 100 \\
\hline
\end{tabular}

\section{Employment}

Unemployed 37.5

Employed (full-time)

50

Employed (part-time)

12.5

\section{Aged-out of foster care}

100

History of homelessness 100

History of trauma 100 $(\mathrm{n}=8)$ identified as Black or African American. The age of the sample ranged from 21-24 years old, with the mean age being 22 years. Thus, this population met the definition of young adulthood in standard guidelines (McDonagh et al., 2018). Demographics are reported in Table 1. Individual participants were provided a $\$ 10$ weekly incentive to attend, which was provided at the end of each session. Funding for the incentive was provided through the organization's apprenticeship program grant. The study was approved by the Institutional Review Board at the sponsoring university and signed informed consent was obtained from all participants.

\section{Measures}

The Perceived Stress Scale (PSS-10) and Goal Attainment Scale (GAS) were used to monitor change resulting from the occupational therapy educational group protocol, with the PSS-10 used as a pretest-posttest assessment. The PSS-10 is a self-report scale which measures the extent to which an individual perceives current life situations as stressful (Lee, 2012). The tool consists of 10 questions (6 negative and 4 positive), which are rated on a 5-point Likert scale (Lee, 2012). Designed for use in community settings, with individuals who have at least a middle school education (Taylor, 2015), the PSS-10 was appropriate for use with the study sample. The PSS10 functioned as a quick and accessible measure for the young adults, and through limiting perceptions to a one-month period of time, it allowed for the posttest to track progress specifically during the time when the group protocol was being implemented. The PSS-10 was provided to each participant at the start of the first week's session, prior to any group content being delivered. Participants completed the assessment individually, without input from each other or the co-authors. Progress was monitored through analyzing the difference in participants' perceived stress prior to and after implementation of the eight-week occupational therapy educational training group protocol.

The Goal Attainment Scale allows for individualized scales of evaluation to be established 
Student Journal of Occupational Therapy, 2(2), 15-27

Table 2

Example of Participant's Goal Attainment Scale

\begin{tabular}{|c|c|c|c|c|}
\hline-2 & -1 & $\mathbf{0}$ & 1 & 2 \\
\hline $\begin{array}{l}\text { The participant is } \\
\text { currently able to } \\
\text { identify } 1 \text { coping } \\
\text { strategy that is } \\
\text { used during times } \\
\text { of agitiaion. }\end{array}$ & $\begin{array}{l}\text { In order to promote } \\
\text { appropriate anger } \\
\text { management, the } \\
\text { participant will } \\
\text { identify and utilize } \\
2 \text { coping strategies } \\
\text { in times of } \\
\text { agitation. }\end{array}$ & $\begin{array}{l}\text { In order to promote } \\
\text { appropriate anger } \\
\text { management, the } \\
\text { participant will } \\
\text { identify and utilize } 3 \\
\text { coping strategies in } \\
\text { times of agitation. }\end{array}$ & $\begin{array}{l}\text { In order to promote } \\
\text { appropriate anger } \\
\text { management, the } \\
\text { participant will } \\
\text { identify and utilize } \\
4 \text { coping strategies } \\
\text { in times of } \\
\text { agitation. }\end{array}$ & $\begin{array}{l}\text { In order to promote } \\
\text { appropriate anger } \\
\text { management, the } \\
\text { participant will } \\
\text { identify and utilize } \\
5 \text { coping strategies } \\
\text { in times of } \\
\text { agitation. }\end{array}$ \\
\hline
\end{tabular}

for clients such that progress can be monitored over time (Krasny-Pacini et al., 2013). GAS has been shown to have high sensitivity to change in a variety of different environments and with different populations (Mulcahey \& Kozin, 2014); it has also shown increased sensitivity to change when compared to both the Barthel Index and Functional Independence Measure (Krasny-Pacini et al., 2013). Overall, inter-rater reliability has demonstrated the potential to be strong (Fleiss kappa $k=0.92$ ) however, this can vary greatly (Krasny-Pacini et al., 2013). It is important to note that research showed increased inter-rater reliability when the GAS is established by the therapist working with the client (Krasny-Pacini et al., 2013).

Subsequently, in one-on-one meetings with participants, the co-authors worked with each individual to establish a realistic and appropriate goal to be achieved by the end of the eight-week period. The goal was then scaled on a five-point scale where " 2 " represented the individual's baseline level, "-1" represented progress without goal attainment, " 0 " was the expected outcome and reflected the goal established with the participant, " +1 " represented a better than expected outcome, and " +2 " reflected the best possible outcome (Krasny-Pacini et al., 2013), as laid out in Table 2. Due to its nature and design, the GAS was tailored to the specific employment and/or education objectives of each young adult participating in the study. Progress was monitored through calculating the change in each participant's goal from their baseline at "-2".

\section{Description of Group Programming}

The framework for the occupational therapy educational training group was structured in alignment with Cole's Seven Steps (2012) under the umbrella of the Transtheoretical Model (Prochaska \& DiClemente, 1982). The group focus was on developing foundational IADL skills, which have been shown to positively impact both employment and education outcomes (Muñoz et al., 2005; Thomas et al., 2011). The curriculum was developed by the researchers using an occupational therapy lens with a heavy focus on active participation.

Eight weekly sessions were created to include tailored activities to meet the needs of individuals who identified as being in the different stages ranging from pre-contemplation to action (Prochaska \& DiClemente, 1982) as determined by pre-programming Goal Attainment Scale (GAS) interviews. They consisted of a warm-up to build group cohesion, a "hands-on" activity that involved "doing" and application to the goal for the week, followed by the encouragement of sharing and processing to elicit how the activity made the young adults feel. Participants were then encouraged to generalize and apply the week's content to "demonstrate" how the activity of the week "applied" to daily life. Weekly content repeatedly 
tied back to the goals of employment acquisition, job maintenance and perceived stress, and frequently incorporated game-based and mildly competitive elements to increase motivation and active participation amongst this population (Gaudet-Blavignac \& Geissbuhler, 2012; Shandley et al., 2010), components which are at the heart of occupational therapy practice. The last step of each weekly session also included a summary of events led by the group leader in order to highlight the key points of the session with an emphasis placed on the application of learned concepts to daily life (employment goals). The one-hour group sessions were conducted onsite at the organization's urban locations where participants resided. Voluntary group attendance was no larger than eight participants per week. In keeping with the values of occupational therapy practice, the weekly group content involved active and cooperative learning strategies with active participation from all individuals heavily encouraged (Muñoz et al., 2005; Thomas et al., 2011). The occupational therapy educational training group protocol utilized an occupation-based perspective to target the IADL needs identified in the literature as commonly associated with education and employment barriers among the young adult population (Barnow et al.,

Table 3

Group Session Curriculum

Week Group Session Curriculum

1 Physiological Response to Stress

Identification of Stressful Situations in

2 the Employment/Education Settings \& How to Respond

3 Healthy Communication Strategies

4 Letting Go of Expectations

5 Finance Management

6 Time Management

7 Anger Management

8 Development of "Coping Skill Toolbox"
2015; Thomas et al., 2011). In recognition of this, the implementation of effective coping skills education and stress management strategies (Muñoz et al., 2005; Thomas et al., 2011) were at the core of each one-hour group session (See table $3)$.

\section{Data Analysis}

SPSS Version 25 was used to analyze all results. A Wilcoxon signed-rank test was conducted to examine the difference in participants' PSS-10 scores pre/post group programming in order to determine statistical significance at a p-value of $\leq$ 0.05 . Pre/post-test scores on the GAS were delineated and compared through the use of a bar graph. All data was reviewed by a universitysponsored research coordinator for accuracy.

\section{Results}

Results of the "Don't STRESS it" group protocol indicated that the eight-week occupational therapy educational training group protocol positively impacted participants' progress towards their individually created employment/education-related goals as demonstrated through pre/post scores using the Goal Attainment Scale. All participants were considered to have completed the "Don't STRESS it!" group protocol, regardless of attendance. Through review of the individual goal attainment scales, all of the participants reported positive progress towards goals, with seven of eight participants surpassing the expected established outcome (see Figure 1).

\section{Perceived Stress Levels}

Results demonstrated that $88 \%$ (7 of 8 participants) of participants underwent a positive change in their PSS-10 scores, with only one participant reporting an increase in perceived stress following implementation of the group protocol (see Figure 2); mean PSS-10 scores indicated an improvement from 18.250 pre to 11.625 post. A Wilcoxon signed-rank test showed no statistically significant change in participants' PSS-10 scores from pretest 
Student Journal of Occupational Therapy, 2(2), 15-27

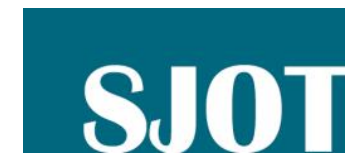

\section{Figure 1}

\section{GAS Outcomes}

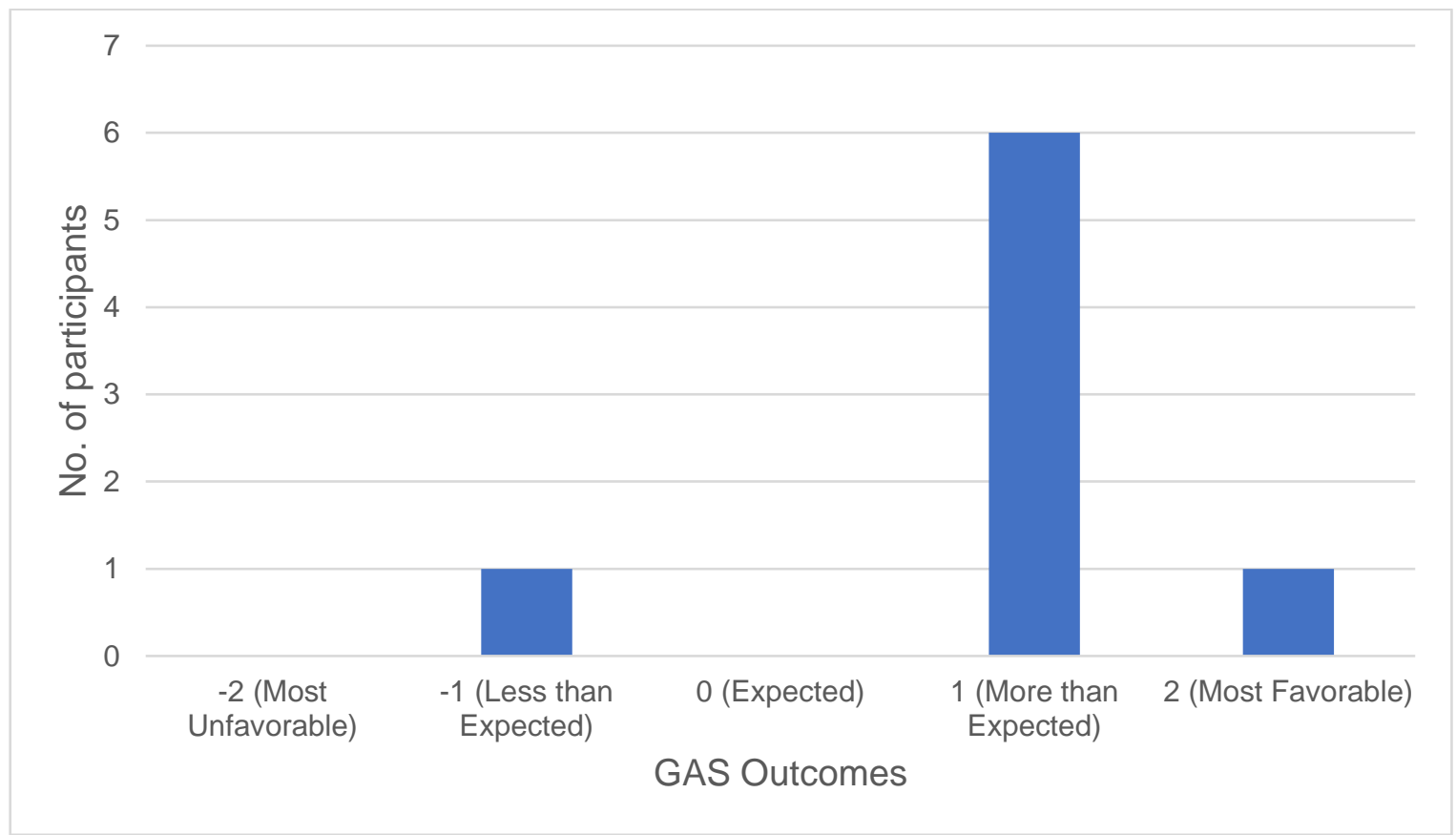

Figure 2

Participant Change in PSS-10 Score

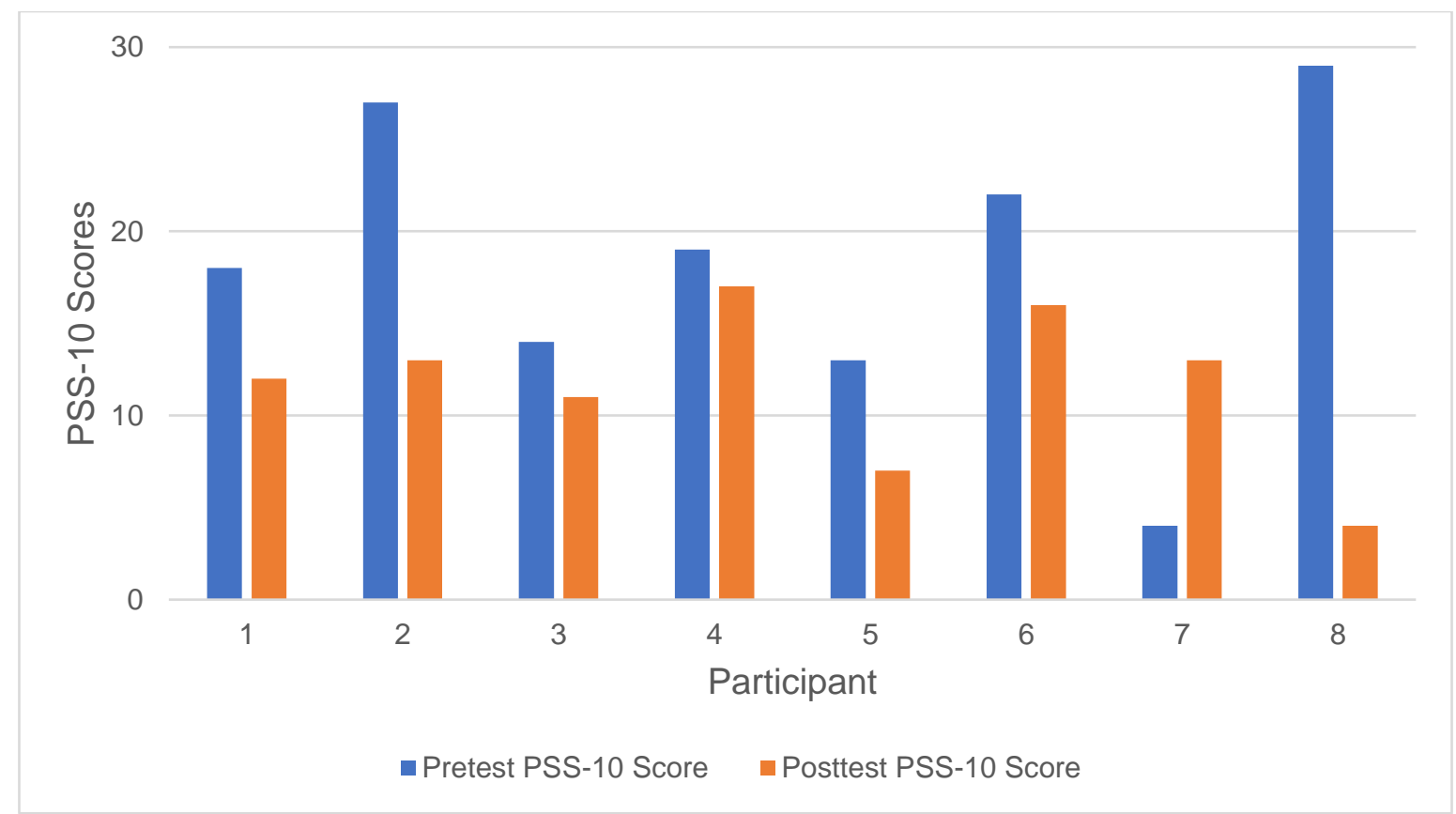


to posttest, although a trend towards significance was noted $(Z=-1.689, p=0.91)$.

\section{Post Group Participant Feedback}

To capture satisfaction with the eight-week occupational therapy educational training group protocol, participants were asked to provide written feedback at the conclusion of the last group session. Participants were prompted to write one thought feeling related to the eight-week group content. Positive verbatim responses are listed here:

"Memorable,"

"I learned to smell the flowers and blow out the candles,"

"Helpful $\rightarrow$ Deep Breathing ... Remembering you cannot control everything. Just breathe,"

"These groups have been extremely therapeutic and an experience of a lifetime, I got to express my opinions and be who I am,"

"This group was...awsome[sic]...helpful (very),"

"Time management, anger, stress, ya'll cool appreciate the "adult" help" "Fun".

This information was not taken into account during the analysis of results but is recorded as a means to inform future occupational therapy programming within the organization.

\section{Discussion}

Potential underdevelopment of certain IADL skills and the use of maladaptive stress management and coping strategies have been linked to poor employment and education outcomes amongst young adults who have aged out of the foster-care system (Barnow et al., 2015; Bond et al., 2015; Everson-Hock et al., 2011; Muñoz et al., 2005; Tandon et al., 2015; Thomas et al., 2011). Longterm maintenance of employment, or unemployment, correlates with increased strains on work-life balance, professional and personal relationships and augmented financial demands, all of which have the potential to increase one's stress level (Schneider et al., 2011). To address these potentially underdeveloped IADL skills and increased perception of stress, this study aimed to explore the effect of an occupational therapy educational training group on the perceived stress levels and employment/education-related goal achievement of young adults who have aged out of the foster-care system and who have a history of chronic homelessness and trauma.

Findings were consistent with previous, but limited, literature surrounding occupational therapy intervention with the homeless population in regards to employment (Muñoz et al., 2005; Thomas et al., 2011), suggesting that service provision through the unique lens of occupational therapy may have the potential to be a complementary and vital component of service provision models in community-based settings. Also notable was the observation that overall group cohesion increased during sessions that involved game-based and mildly competitive activities. This information may be utilized to inform future occupational therapy group content designed for young adults, where the use of games is seen as an appropriate and engaging means to facilitate participation among this population in a community-based program (Gaudet-Blavignac \& Geissbuhler, 2012; Shandley et al., 2010).

Due to the eight-week, one-hour long structure of the occupational therapy educational training group, topic areas were only addressed once during the weekly sessions. However, via observations and through reviewing the narrative feedback, it is noted that coping strategies which were referenced more than once during the program were better retained by participants. This can be seen specifically in the case of "deep breathing," which $25 \%$ of participants referenced in their feedback. Subsequently, it is hypothesized that had time allowed for two consecutive weeks of groups focused on areas such as time management and finance management, this content may also have seen higher retention rates and carryover amongst participants (Tabibian et al., 2019).

Additionally, a participant's readiness to change 
may also have contributed to the progress made as a result of group programming. As previously highlighted, an individual's motivation plays a substantial role in their success following participation in support services (Hoven et al., 2016). An individual who identified in either the pre-contemplation or contemplation stage of change may not have been as committed to their goal as an individual in the action stage (Prochaska $\&$ DiClemente, 1982). Consequently, the use of a change assessment scale, such as the University of Rhode Island Change Assessment Scale (URICA), may be beneficial to both establish the participants' stage of change at the start of programming and, if the individual is in the pre-contemplation or contemplation stage, determine if programming has the potential to support their progression into the next stage.

While some participants established similar goals via GAS, several were working towards distinct goals. Regardless, all participants reported positive progress toward their individual goals at the close of the study. This outcome suggests that an occupational therapy approach to group programming, measured by GAS, may be an appropriate method to utilize when working towards differing goals with individuals in a group setting. Both the PSS-10 and GAS have been shown to be effective methods of capturing results with the young adult population. The accessibility, appropriateness and low cost of each tool indicates the need for clinicians to consider these assessments when working in a community-based setting.

\section{Limitations}

This doctoral capstone study is not without limitations. The small convenience sample size (n $=8$ ), was conducted in collaboration with one organization only, limiting the generalizability and significance of the results. Additionally, the outcome measures for this research are self-report tools, and therefore results may have been subject to response bias. Observer bias may also have been present as the researchers were not blinded, but instead were responsible for both working with participants to establish their individualized GAS and for implementing the group protocol. Attendance across the eight-week period was also inconsistent, which may have negatively impacted the overall results. Only three of eight participants attended all sessions of the eight-week group protocol; four of eight participants attended seven of the eight group sessions and one participant was present for just five of the eight weeks. Lastly, even with incentivized attendance ( $\$ 10 /$ session provided by the program's grant), participant turnout was inconsistent, and therefore exploration of stronger incentives focused towards the wants/needs of the participants are recommended.

\section{Conclusion}

In summary, the current study supports previous findings which showed the positive relationship between life skill development and perceived stress level in relation to education/employment-related goals in young adults aging out of foster care. The clinical significance obtained through GAS, in combination with the statistical significance of the PSS-10, suggest that further research may be beneficial to better determine transferability of the "Don't STRESS it!" group protocol study. It is recommended that future research also aims to have a larger sample size while maintaining an adequate group size to support active engagement by all (Higgins et al., 2015). Additional positive outcomes may also be obtained through a longitudinal study.

Overall, occupational therapy group-based services have been shown to be an effective means through which to target the areas of IADL and stress management with potentially promising results, in particular amongst young adults who have aged out of the foster-care system and have a history of chronic homelessness and trauma. Further research is recommended to confirm generalizability of the results of this exploratory research study. 


\section{References}

American Occupational Therapy Association. (2020). Occupational therapy practice framework: Domain and process (4th ed.). American Journal of Occupational Therapy, 74(Suppl. 2), 7412410010. https://doi.org/10.5014/ajot.2020.74S2001

Barnow, B. S., Buck, A., O’Brien, K., Pecora, P., Ellis, M. L., \& Steiner, E. (2013). Effective services for improving education and employment outcomes for children and alumni of foster care service: Correlates and educational and employment outcomes. Child \& Family Social Work, 20(2), 159-170. https://doi.org/10.1111/cfs.12063

Bond, G. R., Drake, R. E., \& Becker, D. R. (2012). Generalizability of the Individual Placement and Support (IPS) model of supported employment outside the US. World Psychiatry, 11(1), 32-39. https://doi.org/10.1016/j.wpsyc.2012.01.005

Bond, G. R., Drake, R. E., \& Pogue, J. A. (2019). Expanding Individual Placement and Support to Populations With Conditions and Disorders Other Than Serious Mental

Illness. Psychiatric services, 70(6), 488-498. https://doiorg.proxy1.lib.tju.edu/10.1176/appi.ps.201800 $\underline{464}$

Bond, G. R., Kim, S. J., Becker, D. R., Swanson, S. J., Drake, R. E., Krzos, I. M., Fraser, V. V., O’Neill, S., \& Frounfelker, R. L. (2015). A controlled trial of supported employment for people with severe mental illness and justice involvement. Psychiatric Services, 66(10), 1027-1034.

https://doi.org/10.1176/appi.ps.201400510

Cole, M. B. (2012). Group dynamics in occupational therapy: The theoretical basis and practice application of group intervention. SLACK Inc.

Cougle, J. R., Resnick, H., \& Kilpatrick, D. G. (2009). Does prior exposure to interpersonal violence increase risk of PTSD following subsequent exposure? Behaviour Research and Therapy, 47(12), 1012-1017. http://dx.doi.org/10.1016/j.brat.2009.07.014

Davies, B. R., \& Allen, N. B. (2017). Trauma and homelessness in youth: Psychopathology and intervention. Clinical Psychology Review, 54, $17-28$. https://doi.org/10.1016/j.cpr.2017.03.005

Everson-Hock, E. S., Jones, R., Guillaume, L., Clapton, J., Duenas, A., Goyder, E., Chilcott, J., Cooke, J., Payne, N., Sheppard, L. M., \& Swann, C. (2011). Supporting the transition of looked-after young people to independent living: a systematic review of interventions and adult outcomes. Child: Care, Health and Development, 37(6), 767-779. https://doi.org/10.1111/j.13652214.2011.01287.x

Ferguson, K. M. (2018). Employment outcomes from a randomized controlled trial of two employment interventions with homeless youth. Journal of the Society for Social Work and Research, 9(1), 1-21. https://doi.org/10.1086/696372

Ferguson, K. M., Xie, B., \& Glynn, S. (2011). Adapting the Individual Placement and Support Model with Homeless Young Adults. Child \& Youth Care Forum, 41(3), 277-294. https://doi.org/10.1007/s10566-011-9163-5

Gaudet-Blavignac, C., \& Geissbuhler, A. (2012). Serious games in health care: A survey. Yearbook of Medical Informatics, 7, 30-33. https://pubmed.ncbi.nlm.nih.gov/22890338/

Gray, H. M., Nelson, S. E., Shaffer, H. J., Stebbins, P., \& Farina, A. R. (2017). How do homeless adults change their lives after completing an intensive job-skills program? A prospective study. Journal of Community Psychology, 45(7), 888-905. https://doi.org/10.1002/jcop.21900

Heerde, J. A., Hemphill, S. A., \& Scholes-Balog, K. E. (2016). The impact of transitional programmes on post-transition outcomes for youth leaving out-of-home care: A meta- 
analysis. Health \& Social Care in the

Community, 26(1), e15-e30.

https://doi.org//10.1111/hsc. 12348

Higgins, S., Schwatrzberg, S., Bedell, G., \& Duncombe, L. (2015). Current Practice and Perceptions of Group Work in Occupational Therapy. American Journal of Occupational Therapy, 69(Suppl. 1), 1. https://doi.org/10.5014/ajot.2015.69S1$\underline{\mathrm{PO} 7096}$

Hoven, H., Ford, R., Willmot, A., Hagan, S., \& Siegrist, J. (2016). Job coaching and success in gaining and sustaining employment among homeless people. Research on Social Work Practice, 26(6), 668-674. https://doi.org/10.1177/1049731514562285

Kannenberg, K., \& Boyer, D. (1997). Occupational therapy evaluation and intervention in an employment program for homeless youths. Psychiatric Services, 48(5), 631-633. https://doi.org/10.1176/ps.48.5.631

Krasny-Pacini, A., Hiebel, J., Pauly, F., Godon, S., \& Chevignard, M. (2013). Goal attainment scaling in rehabilitation: a literature-based update. Annals of Physical and Rehabilitation Medicine, 56(3), 212-230.

https://doi.org/10.1016/j.rehab.2013.02.002

Kukla, M., \& Bond, G. R. (2009). The working alliance and employment outcomes for people with severe mental illness enrolled in vocational programs. Rehabilitation Psychology, 54(2), 157-163. https://doi.org/10.1037/a0015596

Lee, E. (2012). Review of the psychometric evidence of the perceived stress scale. Asian Nursing Research, 6(4), 121-127. https://doi.org/10.1016/j.anr.2012.08.004

Lee, T., \& Morgan, W. (2017). Transitioning to adulthood from foster care. Child and Adolescent Psychiatric Clinics of North America, 26(2), 283-296. https://doi.org/10.1016/j.chc.2016.12.008

Marshall, T., Goldberg, R. W., Braude, L., Dougherty, R. H., Daniels, A. S., Ghose, S. S.,
George, P., \& Delphin-Rittmon, M. E. (2014). Supported employment: assessing the evidence. Psychiatric Services, 65(1), 16-23. https://doi-

org.proxy1.lib.tju.edu/10.1176/appi.ps.201300 $\underline{262}$

McDonagh, J. E., \& European Training Effective Care and Health Faculty (2018). The age of adolescence.... and young adulthood. The Lancet Child \& Adolescent Health, 2(4), e6. https://doiorg.proxy1.lib.tju.edu/10.1016/S23524642(18)30079-8

Mulcahey, M.J., \& Kozin, S.H. (2014) Outcome Measures. In Abzug, J. M., Kozin, S. H., \& Zlotolow, D. A. (2015). The Pediatric Upper Extremity (Vol. 1). Springer.

Muldoon, O. T., Haslam, S. A., Haslam, C., Cruwys, T., Kearns, M., \& Jetten, J. (2019). The social psychology of responses to trauma: social identity pathways associated with divergent traumatic responses. European Review of Social Psychology, 30(1), 311-348. https://doi.org/10.1080/10463283.2020.17116 28

Muñoz, J. P., Reichenbach, D., \& Hansen, A. M. W. (2005). Project Employ: engineering hope and breaking down barriers to homelessness. Work (Reading, Mass.), 25(3), 241-252. https://pubmed.ncbi.nlm.nih.gov/16179773/

Poremski, D., Rabouin, D., \& Latimer, E. (2017). A randomised controlled trial of evidence based supported employment for people who have recently been homeless and have a mental illness. Administration and Policy in Mental Health, 44(2), 217-224. https://doi.org/10.1007/s10488-015-0713-2

Poremski, D., Whitley, R., \& Latimer, E. (2016). Building trust with people receiving supported employment and housing first services. Psychiatric Rehabilitation Journal, 39(1), 20 26. https://doi.org/10.1037/prj0000137

Prochaska, J. O., \& DiClemente, C. C. (1982). Transtheoretical therapy: Toward a more 
integrative model of change. Psychotherapy: Theory, Research \& Practice, 19(3), 276-288. https://doi.org/10.1037/h0088437

Rosenheck, R. A., \& Mares, A. S. (2007). Implementation of supported employment for homeless veterans with psychiatric or addiction disorders: two-year outcomes. Psychiatric Services, 58(3), 325-333. https://doi.org/10.1176/ps.2007.58.3.325

Schneider, B., Grebner, K., Schnabel, A., Hampel, H., Georgi, K., \& Seidler, A. (2011). Impact of employment status and work-related factors on risk of completed suicide. A case-control psychological autopsy study. Psychiatry Research, 190(2-3), 265-270. https://doi.org/10.1016/j.psychres.2011.07.037

Semanchin Jones, A., Bowen, E., \& Ball, A. (2018). "School definitely failed me, the system failed me": Identifying opportunities to impact educational outcomes for homeless and child welfare-involved youth. Children and Youth Services Review, 91, 66-76. https://doi.org/10.1016/j.childyouth.2018.05.0 $\underline{32}$

Shandley, K., Austin, D., Klein, B., \& Kyrios, M. (2010). An evaluation of "Reach Out Central": an online gaming program for supporting the mental health of young people. Health Education Research, 25(4), 563-574. https://doi.org/10.1093/her/cyq002

Stewart, C. J., Kum, H.-C., Barth, R. P., \& Duncan, D. F. (2014). Former foster youth: Employment outcomes up to age 30. Children and Youth Services Review, 36, 220-229. https://doi.org/10.1016/j.childyouth.2013.11.0 24

Tabibian, B., Upadhyay, U., De, A., Zarezade, A., Schölkopf, B., \& Gomez-Rodriguez, M. (2019). Enhancing human learning via spaced repetition optimization. Proceedings of the National Academy of Sciences of the United
States of America. 116(10), 39988-3993. https://doi.org/10.1073/pnas.1815156116

Tandon, S. D., Latimore, A. D., Clay, E., Mitchell, L., Tucker, M., \& Sonenstein, F. L. (2015). Depression outcomes associated with an intervention implemented in employment training programs for low-income adolescents and young adults. JAMA Psychiatry, 72(1), 31-39. https://doi.org/10.1001/jamapsychiatry.2014.2 022

Taylor, J. M. (2015). Psychometric analysis of the Ten-Item Perceived Stress Scale.

Psychological Assessment, 27(1), 90-101. https://doi.org/10.1037/a0038100

The HABITS Lab at UMBC. (2019). Health and addictive behaviors: Investigating

Transtheoretical. University of Maryland, Baltimore County. https://habitslab.umbc.edu/urica/

Thomas, Y., Gray, M., \& McGinty, S. (2011). A systematic review of occupational therapy interventions with homeless people. Occupational Therapy in Health Care, 25(1), $38-53$.

https://doi.org/10.3109/07380577.2010.52855 4

Villagrana, K. M., Mody, E. H., Lawler, S. M., Wu, Q., \& Ferguson, K. M. (2020).

Educational outcomes for homeless young adults with and without a history in foster care. Children and Youth Services Review, 116, 105153. https://doi.org/10.1016/j.childyouth.2020.1051 53

Zona, K., \& Milan, S. (2011). Gender differences in the longitudinal impact of exposure to violence on mental health in urban youth. Journal of Youth and Adolescence, 40(12), 1674-1690. http://dx.doi.org/10.1007/s10964$\underline{011-9649-3}$ 